\title{
BMJ Open A qualitative study of stakeholder views regarding participation in locally commissioned enhanced optometric services
}

\author{
E Konstantakopoulou, ${ }^{1}$ R A Harper, ${ }^{2}$ D F Edgar, ${ }^{1}$ J G Lawrenson ${ }^{1}$
}

To cite:

Konstantakopoulou $\mathrm{E}$, Harper RA, Edgar DF, et al. A qualitative study of stakeholder views regarding participation in locally commissioned enhanced optometric services. BMJ Open 2014;4: e004781. doi:10.1136/ bmjopen-2013-004781

- Prepublication history and additional material is available. To view please visit the journal (http://dx.doi.org/ 10.1136/bmjopen-2013004781)

Received 31 December 2013 Revised 4 April 2014 Accepted 9 May 2014

CrossMark

\begin{abstract}
${ }^{1}$ Centre for Public Health Research, School of Health Sciences, City University London, London, UK ${ }^{2}$ Manchester Royal Eye Hospital, Central Manchester University Hospitals NHS Foundation Trust, Manchester Academic Health Science Centre, Manchester, UK
\end{abstract}

Correspondence to Professor J G Lawrenson; j.g.lawrenson@city.ac.uk

\author{
ABSTRACT \\ Objectives: To explore the views of optometrists, \\ general practitioners (GPs) and ophthalmologists \\ regarding the development and organisation of \\ community-based enhanced optometric services. \\ Design: Qualitative study using free-text \\ questionnaires and telephone interviews.
}

Setting: A minor eye conditions scheme (MECS) and a glaucoma referral refinement scheme (GRRS) are based on accredited community optometry practices. Participants: 41 optometrists, 6 ophthalmologists and 25 GPs.

Results: The most common reason given by optometrists for participation in enhanced schemes was to further their professional development; however, as providers of 'for-profit' healthcare, it was clear that participants had also considered the impact of the schemes on their business. Lack of fit with the 'retail' business model of optometry was a frequently given reason for non-participation. The methods used for training and accreditation were generally thought to be appropriate, and participating optometrists welcomed the opportunities for ongoing training. The ophthalmologists involved in the MECS and GRRS expressed very positive views regarding the schemes and widely acknowledged that the new care pathways would reduce unnecessary referrals and shorten patient waiting times. GPs involved in the MECS were also very supportive. They felt that the scheme provided an 'expert' local opinion that could potentially reduce the number of secondary care referrals.

Conclusions: The results of this study demonstrated strong stakeholder support for the development of community-based enhanced optometric services. Although optometrists welcomed the opportunity to develop their professional skills and knowledge, enhanced schemes must also provide a sufficient financial incentive so as not to compromise the profitability of their business.

\section{INTRODUCTION}

During the past 45 years, the National Health Service General Ophthalmic Services

\section{Strengths and limitations of this study}

- This is the first study to describe the views and attitudes of optometrists and other key stakeholders regarding the development and operation of community-based enhanced optometric services.

- Importantly, the study also investigated reasons for optometrist non-participation.

- All the ophthalmologists surveyed were actively involved in the development and operation of the schemes and their views may not be representative of all UK ophthalmologists.

(GOS) has provided a clinically effective and cost-effective system for provision of community eye care, encompassing detection and correction of refractive errors and opportunistic case finding for eye disease. In recent years, notable changes in statutory legislation have had a direct impact on the scope of optometric practice. In 2000, an amendment to the General Optical Council (GOC) 'Rules relating to injury or disease of the eye' allowed community optometrists, for the first time, to decide not to refer patients with a disease or abnormality of the eye to a medical practitioner if there was no justification to do so. ${ }^{1}$ In 2005, the rules were further changed to allow referral to a more specialist optometrist colleague with appropriate qualifications or expertise to manage the patient. ${ }^{2}$ In parallel with these changes, amendments to medicines legislation have facilitated access to therapeutic agents. Consequently, the last decade has witnessed significant changes to the role boundaries of UK optometrists, through creation of new clinical roles, together with an expansion of existing roles.

A review of the scope, structure and organisation of the GOS was commissioned by the Department of Health in 2005. ${ }^{3}$ The primary focus of the review was to examine how to 
support healthcare commissioners in the development of a wider range of community-based eye care services. The review recommended the establishment of a threetiered GOS framework consisting of:

- essential services, that is, provision of standard GOS sight tests;

- additional services, for example, domiciliary sight testing; and

- enhanced services, such as schemes for the treatment and management of acute eye care conditions and community refinement of referrals to the hospital eye service (HES).

Enhanced optometric services have to be locally commissioned and are therefore dependent on the needs of the local population and the configuration of existing eye care services. A variety of enhanced service schemes (ESS) have been commissioned across England, for example, direct cataract referral, ${ }^{4}$ triage of acute eye disease $\mathrm{e}^{56}$ and glaucoma referral refinement. ${ }^{78}$ These schemes aim to relieve part of the HES burden, either by confirming the necessity of referral or by managing the patient in a community setting.

This paper reports on a qualitative study to determine views and attitudes of stakeholders regarding the development and operation of two schemes that are representative of the most commonly commissioned enhanced optometric services: a minor eye conditions scheme (MECS) in South London and a glaucoma referral refinement scheme (GRRS) in Manchester. The study also aims to determine reasons for optometrists' participation or non-participation in such schemes and to make these data available to inform the design of future services.

\section{METHODOLOGY}

\section{Research team}

All authors are optometrists working in academia, the HES and/or primary care settings. One author on the current study $(\mathrm{RH})$ was involved in the design of the GRRS and the training and accreditation for the scheme. No other authors had any prior involvement with either scheme evaluated.

\section{Organisation of the MECS and GRRS}

Under the MECS scheme, patients presenting to their general practitioner (GP) with an eye problem, and satisfying certain inclusion criteria, are referred to specially trained community optometrists. The scheme also allows self-referral to an MECS community optometrist. Awareness of the scheme was raised by widespread local advertising.

In the Manchester GRRS, patients with suspected glaucoma or ocular hypertension following a standard GOS sight test are referred to accredited community optometrists working within their own practices, instead of the usual pathway via the GP and then to the HES. These accredited optometrists work to an agreed set of referral criteria and, depending on whether or not patients meet these criteria, either refer the patients to the Manchester Royal Eye Hospital (MREH) or discharge them. The GRRS was initially launched in 2000 and was recently updated to include measurement of central corneal thickness.

For both schemes, accredited community optometrists were remunerated for their services by the Clinical Commissioning Group.

\section{Design, participants and data collection}

The method chosen for qualitative data collection was adapted for each target group to maximise response rates (table 1). Methods included: free-text paper based or online questionnaires or semistructured telephone interviews.

The sampling strategy was designed to be inclusive and capture the views of healthcare professionals participating in community schemes and their associated care pathways. These included: all MECS and GRRS optometrists, as well as other key stakeholders (participating ophthalmologists, specialist hospital optometrists and GPs). The views of non-participating optometrists, who had been invited to join the schemes but chose not to, were also sought.

A topic guide was developed by the research team, in consultation with the Enhanced Scheme Evaluation Project (ESEP) Steering Group (a multidisciplinary group consisting of optometrists, ophthalmologists and methodologists). The guide formed the basis for openended questions used in questionnaires and telephone interviews (see online supplementary file 'Topic Guide). The topic guide covered the following broad subject areas:

- Enablers and barriers to pathway adoption

- Views on the impact of ESS on community optometry practices and existing eye care services

- Views on training and accreditation

- Frequency and quality of interprofessional communication

Each scheme had different groups of participants, described in table 1. Both the MECS and GRRS included community optometrists and ophthalmologists. GPs were also important stakeholders within the MECS as service users, while glaucoma specialist hospital optometrists participated in the GRRS as trainers and also received referrals from GRRS accredited optometrists. A total of 10 optometrists and 4 ophthalmologists were involved in the MECS and all were contacted for their views as part of the MECS evaluation, while 2 ophthalmologists, 17 community optometrists and 4 hospitalbased glaucoma specialist optometrists were in the GRRS and all were contacted for their views regarding the GRRS. A total of 25 GPs who attended a regional educational event in South London, which focused on the MECS, were contacted. Finally, 32 optometrists who had been invited to participate in either the MECS or GRRS by their Local Optical Committee but opted not 
Table 1 Healthcare professionals approached for the purposes of this study for the MECS and GRRS

\begin{tabular}{|c|c|c|c|c|}
\hline & \multicolumn{2}{|c|}{ MECS } & \multicolumn{2}{|c|}{ GRRS } \\
\hline & $\overline{\mathbf{N}}$ & Data collection method & $\overline{\mathbf{N}}$ & Data collection method \\
\hline Participating optometrists & 10 & Semistructured online questionnaire & 17 & Semistructured online questionnaire \\
\hline Participating ophthalmologists & 4 & Semistructured online questionnaire & 2 & Semistructured online questionnaire \\
\hline GPs & 25 & Semistructured paper-based questionnaire & & $\mathrm{N} / \mathrm{A}$ \\
\hline Glaucoma specialist optometrists & & N/A & 4 & Semistructured online questionnaire \\
\hline Non-participating optometrists & 13 & Semistructured telephone interview & 19 & Semistructured online questionnaire \\
\hline
\end{tabular}

to participate were also invited to provide their views. Each group contacted (eg, optometrists, GPs, etc) was asked to respond to a series of open-ended free-text questions that were adapted to their role.

\section{Data analysis}

Data from online surveys, telephone interviews and paper-based questionnaires were transferred into an Excel spreadsheet. One researcher (EK) conducted the initial process of coding and thematic analysis. ${ }^{9}$ During this process, responses were reviewed line by line and as each emerging concept was identified, it was assigned a code. Identically coded sections of each response or transcript were compared to check whether they represented the same concept. Through this iterative process, emerging themes were identified and interpreted. Other team members (RAH, JGL and DFE) reviewed codes and emerging themes, discussed and resolved minor disagreements and all authors reached a consensus on interpretation.

The study was approved by the Research and Ethics committee of the School of Health Sciences, City University London. The research followed the principles of the Declaration of Helsinki.

\section{RESULTS}

Of the 94 healthcare professionals contacted, a total of 74 responses were received, an overall response rate of $78.7 \%$. Table 2 shows the response rate for each professional group.

The results of the qualitative analysis for each group of healthcare professionals are presented below using subheadings to reflect each thematic domain.

\section{Participating community optometrists}

Reasons for participation

The most evident reason for participation among the GRRS and MECS community optometrists was to further their professional development. Optometrists felt that participation in ESS would allow them to be exposed to more challenging clinical cases and consequently have opportunities to use their clinical skills to a greater extent. Interestingly, glaucoma specialist optometrists working in the glaucoma clinics in MREH also felt that the GRRS would enhance their own professional role since GRRS would result in the retention of lower risk patients in the community, allowing glaucoma specialist optometrists to deal with a more complex case mix.

Another reason for participation was the perceived benefit for patients and the wider NHS. Community optometrists felt that ESS would improve care pathways for patients in terms of convenience and a reduction in waiting times. The GRRS was also anticipated to enhance the detection of glaucoma in the community by improving participating optometrists' knowledge of the disease and reducing false-positive referrals. Optometrists participating in both schemes were also conscious of potential benefits to the wider NHS in terms of reducing the HES burden and overall healthcare costs. Typical comments included:

[The MECS scheme] frees up the Hospital Eye Service's time and resources to deal with the more serious conditions (MECS community optometrist).

[The GRRS] stops unnecessary referrals to the Hospital Eye Service, therefore saving the tax payer money (GRRS community optometrist).

Table 2 Response rates for healthcare professionals approached for this survey

\begin{tabular}{|c|c|c|c|c|}
\hline & \multicolumn{2}{|l|}{ MECS } & \multicolumn{2}{|l|}{ GRRS } \\
\hline & Approached & Responded (\%) & Approached & Responded (\%) \\
\hline Participating optometrists & 10 & $10(100 \%)$ & 17 & $15(88.2 \%)$ \\
\hline Participating ophthalmologists & 4 & $4(100 \%)$ & 2 & $2(100 \%)$ \\
\hline GPs & $25^{*}$ & $25(100 \%)$ & $\mathrm{N} / \mathrm{A}$ & $\mathrm{N} / \mathrm{A}$ \\
\hline Glaucoma specialist optometrists & $\mathrm{N} / \mathrm{A}$ & $\mathrm{N} / \mathrm{A}$ & 4 & $4(100 \%)$ \\
\hline Non-participating optometrists & 13 & $7(53.8 \%)$ & 19 & 7 (36.8\%) \\
\hline
\end{tabular}


Many optometrists in the schemes revealed that financial incentives and opportunities to develop their business were important drivers for choosing to participate. Approximately $40 \%$ of optometrists participating in the MECS reported that participation was a means of receiving appropriate remuneration for their professional services. In terms of business development, it was felt that patients examined within ESS may subsequently return to the practice for a future sight test. Optometrists within the GRRS also reported that they had joined the scheme to enhance the reputation of their practice and, in some cases, to avoid having to refer their patients to competitors. Typical comments included:

I dislike having to refer pathology to other optometrists for them to decide whether or not it can be referred to the hospital eye service. I would prefer to be able to refer myself. Joining the scheme was the only way to ensure this (GRRS community optometrist).

I enjoy [being part of GRRS] and would not want to [... lose the reputation gained in the eyes of other professionals (GRRS community optometrist).

As an independent we like to be able to offer as many services as possible to our patients. This is another string to our bow; [The GRRS offers] great benefits in keeping the refinement within our own practice (GGRS community optometrists).

[through MECS we see] more patients, hence hopefully these patients come back in the future (MECS community optometrist).

\section{Scheme administration and organisation}

Most participating community optometrists did not encounter any particular administrative difficulties when joining either scheme. An initial setup period was often required to resolve problems (particularly relating to IT issues), but these were generally anticipated by most participants. Most community optometrists within the MECS identified the need to adapt their booking system, for example, keeping free appointments or extending testing times. However, the need for flexibility was acknowledged:

We offer same day or next day appointments for most referrals, and if the symptoms require immediate investigation, those patients will wait and be seen when the optometrist is available. The longest waiting time hitherto, has been 45 minutes (MECS community optometrist).

Although it was not generally felt that extra staff would be required, approximately half of the participating optometrists reported that they needed to train reception staff in a number of MECS/GRRS-related issues, for example, to ensure understanding of the scheme and associated paperwork, recognising urgency of conditions (specific to the MECS) and managing patients.

Although most practices did not feel any obligation to purchase additional equipment to be able to provide services according to the GRRS or MECS protocols, several practices decided to upgrade existing consulting room equipment, for example, slit-lamp, and/or bring forward the purchase of more specialist equipment for example, fundus camera.

\section{Training/accreditation}

Training for the MECS and GRRS included a combination of theoretical learning and HES clinic attendance. For the MECS, theory was taught via an online module, whereas in the GRRS optometrists attended lectures. No MECS optometrists had received any specialised training before participation in the scheme. Approximately $40 \%$ of optometrists new to the GRRS had previously received training relevant to glaucoma or intraocular pressure refinement, while $53 \%$ of participants had been involved in a previous iteration of the Manchester GRRS and been through a similar accreditation process.

The training for the GRRS and MECS was deemed to be appropriate by all participants. Distance learning was regarded as an acceptable mode of delivery for MECS training, although two optometrists would have liked the opportunity to ask questions and others wished that training had included practical sessions. It was also commonly reported by GRRS optometrists that there should have been more time between lectures to allow for better understanding of the content.

Approximately $85 \%$ of the MECS optometrists and all GRRS optometrists identified that training had an overall beneficial effect on their practice, improving clinical knowledge and recognition of clinical signs and clinical decision-making skills.

[The training] has increased my awareness and confidence in managing many conditions within the practice; ...we were given guidelines on when to refer and when not, as this can be a grey area... it was nice for us to be given advice on this (MECS community optometrist).

All GRRS optometrists felt that their glaucoma detection skills had improved significantly, particularly the recognition of potential false-positive cases;

[The training] increased my knowledge on glaucoma and the role of corneal thickness that help to distinguish false positives; [I am] better able to assess whether they are normal, suspect or glaucoma therefore giving the patient a better explanation of the results and not sending them to hospital if a visit can be avoided (GRRS community optometrist).

A minority of participants felt that training requirements had a negative impact on the practice, due to the need to cancel clinics to attend the hospital training, or lectures in the case of the GRRS;

As a locum, the practice did not want me to attend when I was scheduled to work there and would not pay for me 
to attend in their time; but I was willing to attend at another time (GRRS community optometrist).

Almost all participating optometrists in the MECS and GRRS expressed interest in doing more clinical training and had a number of suggestions in terms of their areas of interest. Additional distance learning, gonioscopy, hospital placements and peer review groups were most popular among MECS optometrists, while GRRS optometrists suggested training in gonioscopy, visual field assessment, unusual glaucoma cases and optic nerve head assessment.

\section{Interprofessional communication}

Communication between ophthalmologists/GPs and optometrists was reported to be poor before the beginning of the MECS. The vast majority of optometrists stated that they rarely received feedback on their referrals or the diagnosis of referred patients; where feedback was provided, it generally came from patients. Optometrists primarily wished to receive feedback on the outcome/diagnosis and quality of their referral.

I would like to know what I could do to improve my referrals and what I should not be referring (MECS community optometrist).

Optometrists felt that participation in the MECS would improve communication with secondary eye care services.

Being part of MECS has allowed me to build better relations with GPs and ophthalmology departments (MECS community optometrist).

In terms of the GRRS, good communication between specialist optometrists working in the glaucoma clinic and community optometrists appeared to be well established. Most respondents reported that hospital specialist optometrists provided detailed clinical feedback on their referrals.

I almost always receive useful letters from hospital specialist optometrist. They either agree with my findings (which is reassuring!) or if I'm a bit wide of the mark or have missed something they always word it very tactfully so that I feel I've learned something but without feeling intimidated (GRRS community optometrist).

\section{Non-participating optometrists}

Although the benefits of participation for professional development were recognised, the main reasons given for non-participation for both ESS were: inadequate remuneration, insufficient capacity within the practice, limitations in relation to attending training or succeeding in the accreditation and the perceived administrative burden.

I felt that the rewards would not be sufficient to justify the extra work load and time required to perform all the tests accurately and to the standard required [...] I may refer 3 or 4 patients a month on to GRRS and for that low volume it would not be a problem. My concern was that if we were getting patients referred from other practices for GRRS, this would have an adverse effect on my business. (Non-participating optometrist (GRRS)

Non-participating optometrists believed that participating in the scheme would have required their practice to adapt significantly in terms of its booking system, testing times and purchase of new equipment. A minority expressed a reluctance to undergo additional training. However, despite their personal reservations, most optometrists who chose not to participate had positive views of the schemes.

\section{Medical views}

Ophthalmologists participated for reasons that were more patient centred compared with optometrists: reduction of unnecessary referrals, relieving patient anxiety, improving patient care and reductions in patient waiting times.

All participating ophthalmologists acknowledged that both ESS had the potential to reduce the number of referrals to the HES, as well as HES waiting lists;

This helps us manage the increased suspect glaucoma workload referred to the MREH since the introduction of NICE guidelines for managing glaucoma (GRRS ophthalmologist).

Additionally, it was felt that ESS would result in a higher proportion of patients receiving appropriate treatment.

Ophthalmologists also reported that they participated in ESS to promote better use of healthcare resources and to help optometrists develop their clinical skills;

...this is something most [optometrists] have been doing for years anyway and it is a way of facilitating it... (MECS ophthalmologist)

[I participated to] support the professional development of other healthcare professionals and better use of healthcare resources (GRRS ophthalmologist)

...it is important that ophthalmic practitioners develop the necessary skills to see many of the straightforward problems in primary care (MECS ophthalmologist).

Training and accreditation for both schemes was deemed appropriate by all participating ophthalmologists. It was, however, acknowledged by MECS ophthalmologists that optometrists should have a point of contact should problems arise and highlighted the importance of clinical experience;

....as long as there is someone [the optometrists] can contact where problems arise or things are not clear (MECS ophthalmologist) 
The trouble is that it is probably more 'spot diagnosis' stuff and the huge importance of good history taking and symptoms identification is often secondary. Only experience and sitting in on clinics helps develop this [...] (MECS ophthalmologist)

Ongoing clinical training was supported by GRRS and MECS ophthalmologists;

Optometrists should have a couple of sessions per year in the clinic with consultant team or (glaucoma specialist) optometrists to make sure their skills are still up to date and improving (GRRS ophthalmologist)

[...] the plan is to have much more ongoing training with optometrists attending casualty sessions on a regular basis (MECS ophthalmologist)

However, GRRS ophthalmologists, while acknowledging the commitment required by optometrists to become trained and accredited, also expressed the view that the HES should be compensated for providing training;

[The] hospital would need to be recompensed for the time required to deliver quality training and the community optometrists would need some incentive to be able to leave their practices for the required time for training (GRRS ophthalmologist).

Similarly, for the MECS, time commitments to the scheme and/or the training were also an issue;

If I did not have a paid session of my time dedicated to MECS it would be very difficult to give the scheme the appropriate time (MECS ophthalmologist).

GPs using the MECS reported that they typically saw 2-3 patients with eye problems per week. Almost all GPs thought the MECS would improve care and the 'journey' for patients with eye problems, as well as reduce waiting times. GPs believed that the scheme offers patients more choice and provides a more costeffective and accessible service for minor eye conditions. Some GPs expressed the view that the MECS will make their job easier and potentially reduce their workload. Furthermore, by using optometrists' skills, the scheme would help with those clinical presentations where GPs would normally have some difficulty in making a diagnosis, for example, red eyes, flashes and floaters.

\section{DISCUSSION}

The current study has focused on two locally commissioned ESS: a referral refinement scheme for glaucoma and a triage scheme for minor eye conditions. Although previous studies have evaluated similar schemes in terms of their clinical outcomes and cost effectiveness, ${ }^{4-8}$ these studies did not investigate the views and attitudes of optometrists and other key stakeholders regarding the initial development and overall operation of the schemes.

\section{Reasons for optometrists' participation in ESS}

The relevant Local Optical Committees worked closely with commissioners to develop and implement the schemes. All local optometrists were given the opportunity to participate; however, participants needed to commit to compulsory training and were required to meet the terms of the service specification. The reason most commonly given by optometrists for participating in ESS was to further their professional development. Under the terms of the standard GOS contract in England, optometrists are not obliged to refine their own referrals and receive no additional remuneration for performing discretionary supplementary tests or procedures. Involvement in ESS allows optometrists to make better use of their clinical skills and provides a more challenging case mix. Similarly, specialist optometrists working in hospital glaucoma clinics expressed the opinion that the GRRS would retain lower risk cases in the community and thereby provide more time for them to see more complex cases. Approximately $4 \%$ of the optometric professionals are employed in the HES and hospital optometrists are becoming increasingly involved in extended roles; particularly in glaucoma, medical retina and eye casualty. ${ }^{10}$

Although optometrists expressed views regarding potential benefits to patients from a service redesign of primary eye care, it was also apparent that optometrists had considered the business implications of participation in ESS. Community optometry is a market-driven system that works in partnership with the NHS. The GOS fee represents a declining proportion of practice revenue for optometrists and there has been an increasing cross-subsidisation of sight test costs by sales of optical appliances. ${ }^{11}$ In many cases, optometrists viewed ESS as a means of expanding or developing their business. In the current market-driven system, optometrists must compete with each other, as members of the public are free to consult any eye care provider.

Improved communication and relationship building with other healthcare professionals involved in the patient care pathway (eg, GPs and ophthalmologists) was cited as an additional benefit of participation. Optometrists participating in the MECS reported that prior to the development of the scheme they rarely received feedback on their referrals, thereby denying a much needed learning opportunity. Several studies have previously highlighted the poor communication between community optometrists and the medical profession, particularly lack of feedback on referral. ${ }^{12} 13$ In contrast, the nature of the glaucoma service in Manchester meant that many patients with suspect glaucoma were seen by specialist hospital optometrists and that the GRRS optometrists valued the frequency and quality of the feedback on their referrals received from their hospital colleagues. 
Although all community optometrists were given the opportunity to participate in ESS, only half of the eligible practitioners came forward. The principal reasons for non-participation were the perceived negative impact on their business, insufficient capacity to meet the terms of the service specification or not wishing to purchase new equipment. In some cases, there was a reluctance to undertake the necessary training. Despite these reservations, non-participants generally expressed a positive attitude towards ESS. A recent study of the organisation of eye care services in the West Midlands ${ }^{14}$ found that only a third of the optometrists responding to a survey were involved in any extended role or enhanced service. The reported barriers included lack of time, inadequate remuneration and need for training.

\section{Views on training and accreditation}

Compulsory training was required for both schemes. However, the mode of educational delivery varied; for the MECS, participants had to complete an online training module and were required to attend ophthalmology clinical sessions at the hospital, whereas for the GRRS optometrists completed a didactic training course and attended glaucoma clinics. The need for compulsory training was broadly supported by optometrists and the content of training was deemed to be appropriate. For the MECS, although the distance learning module was generally well received, some expressed the view that they would have liked more practical sessions and an opportunity to ask questions of trainers. Systematic reviews ${ }^{15} 16$ of randomised controlled trials of educational interventions have found that the effectiveness of e-learning is equivalent to traditional delivery methods for the training of healthcare professionals. This finding is relevant to training optometrists for ESS. Distance learning has the advantage that it can be accessed at a time convenient to trainees, particularly important for busy practitioners, who would otherwise need to leave their practices to attend didactic training sessions. However, distance learning is not appropriate for teaching practical clinical skills which would still require attendance at a training course.

\section{Medical views regarding ESS}

The ophthalmologists involved in the MECS and GRRS expressed very positive views regarding ESS. It was widely acknowledged that the new care pathways would reduce unnecessary referrals and shorten patient waiting times. Ophthalmologists were supportive of the professional development of optometrists, although there was recognition of the need for ongoing training to maintain their competency. Particular value was placed on attending further outpatient clinics or eye casualty sessions. The strong interprofessional trust apparent within both schemes was largely due to the close involvement of the ophthalmologists in the development and organisation of the schemes and the delivery of training. The importance of relationship building in reducing interprofessional tensions has been previously reported. ${ }^{17}$

A survey of the views of GPs involved in the MECS demonstrated that they were also very supportive of the scheme. It was generally felt that the MECS would benefit their patients by providing an 'expert' local opinion and could potentially reduce the number of HES referrals.

\section{Strengths and limitations of this study}

A strength of the current study is the representative nature of the two schemes. Schemes that refine referrals for glaucoma or triage acute ophthalmic presentations in the community are among the most widely commissioned ESS. The sampling technique used in the present study attempted to capture a maximum variation of opinions by inviting all participants in the schemes to take part in the qualitative surveys, and there was a good response rate from all stakeholders.

There are some study limitations. Both schemes are exemplars in terms of the level of integration between primary and secondary care. All the ophthalmologists surveyed were actively involved in development of the schemes and in training and accreditation of optometrists. Furthermore, ophthalmologists involved in the MECS were given protected time to support the scheme. Therefore, the positive opinions expressed may be a function of their familiarity with the scheme, and possibly with the individual participants, rather than being representative of all UK ophthalmologists. The poor response rate for optometrists who chose not to participate and the lack of views of non-participating ophthalmologists may also have been a source of bias.

\section{Conclusions}

Optometrists represent a skilled workforce that with further training can provide effective referral refinement and ocular disease management in the community through the provision of ESS. The present study identified that the primary reason for participation in these schemes is the desire to develop professional skills and knowledge. However, 'for profit' providers of healthcare schemes require sufficient financial incentives so as not to compromise business profitability. Optometrists recognised the need for additional training and viewed this favourably whether it was delivered online or face to face. ESS were well received by GPs and by participating ophthalmologists working in secondary care. Both professional groups recognised the advantages of integrating community optometry into eye care pathways to provide an appropriate delivery of care in a convenient community setting. Patients are also important stakeholders and their views of these ESS are currently under investigation and will form the basis of a subsequent publication.

Acknowledgements The authors would like to thank all participants for giving up their time for this study. They would also like to thank the members 
of the Enhanced Scheme Evaluation Project Steering Group for their valuable comments.

Contributors The analysis and interpretation of the data was initially undertaken by EK and checked by JGL, RAH and DFE. The article was drafted by EK and revised by JGL, RAH and DFE. All authors contributed to the design of the study and approved the final version of the article. EK is the guarantor.

Funding This work was supported by a research grant from the College of Optometrists UK.

Competing interests EK's time on this study was funded by the College of Optometrists.

Ethics approval School of Health Sciences Research and Ethics Committee, City University London.

Provenance and peer review Not commissioned; externally peer reviewed.

Data sharing statement Extra data can be accessed via the Dryad data repository at http://datadryad.org/ with the doi:10.5061/dryad.7t3h6

Open Access This is an Open Access article distributed in accordance with the Creative Commons Attribution Non Commercial (CC BY-NC 3.0) license, which permits others to distribute, remix, adapt, build upon this work noncommercially, and license their derivative works on different terms, provided the original work is properly cited and the use is non-commercial. See: http:// creativecommons.org/licenses/by-nc/3.0/

\section{REFERENCES}

1. The General Optical Council (Rules relating to Injury or Disease of the Eye) Order of Council 1999. SI No. 3267. http://www.legislation. gov.uk/uksi/1999/3267/contents/made (accessed 23 Dec 2013).

2. The General Optical Council (Injury or Disease of the Eye and Contact Lens (Qualifications)) (Amendment) Rules Order of Council 2005. SI No. 1476. http://www.legislation.gov.uk/uksi/2005/1476/ made (accessed 23 Dec 2013).

3. Department of Health. General Ophthalmic Services Review. Findings in relation to the framework for primary ophthalmic services, the position of dispensing opticians in relation to the NHS, Local
Optical Committees, and the administration of General Ophthalmic Services payments. Gateway reference: 7689. 2007

4. Park JC, Ross AH, Tole DM, et al. Evaluation of a new cataract surgery referral pathway. Eye (Lond) 2009;23:309-13.

5. Burns DH, Dart JK, Edgar DF. Review of the Camden and Islington Anterior Segment Eye Disease Scheme. Optom Pract 2002;3:55-60.

6. Sheen NJ, Fone D, Phillips CJ, et al. Novel optometrist-led all Wales primary eye-care services: evaluation of a prospective case series. Br J Ophthalmol 2009:93:435-8.

7. Parkins DJ, Edgar DF. Comparison of the effectiveness of two enhanced glaucoma referral schemes. Ophthalmic Physiol Opt 2011;31:343-52.

8. Ratnarajan G, Newsom W, Vernon SA, et al. The effectiveness of schemes that refine referrals between primary and secondary carethe UK experience with glaucoma referrals: the Health Innovation \& Education Cluster (HIEC) Glaucoma Pathways Project. BMJ Open 2013;3:e002715.

9. Braun V, Clarke V. (2006) Using thematic analysis in psychology. Qual Res Psychol 2006;3:77-101.

10. Steele C. Extended roles in hospital optometry and liaison with community optometrists. Opt Pract 2009;9:5-9.

11. Sharma A, Jofre-Bonet M, Panca M, et al. An economic comparison of hospital-based and community-based glaucoma clinics. Eye (Lond) 2012;26:967-71.

12. Whittaker KW, Ikram K, Anderson DF, et al. Non-communication between ophthalmologists and optometrists. $J$ R Soc Med 1999;92:247-8.

13. Needle JJ, Petchey R, Lawrenson JG. A survey of the scope of therapeutic practice by UK optometrists and their attitudes to an extended prescribing role. Ophthalmic Physiol Opt 2008:28:193-203.

14. Hawley C, Albrow H, Sturt J, et al. UK Eye Care Services Project 2010. Phase two: organisation of eye care services in the West Midlands. College of Optometrists. http://www.college-optometrists. org/en/research/commissioned-research-2/index.cfm/ServicesProject (accessed 23 Dec 2013).

15. Cook DA, Levinson AJ, Garside $S$, et al. Internet-based learning in the health professions: a meta-analysis. JAMA 2008;300:1181-96.

16. Wutoh R, Boren SA, Balas EA. eLearning: a review of Internet-based continuing medical education. J Contin Educ Health Prof 2004;24:20-30.

17. O'Connor PM, Harper CA, Brunton CL, et al. Shared care for chronic eye diseases: perspectives of ophthalmologists, optometrists and patients. Med J Aust 2012;196:646-50. 